\title{
PV DOMESTIC HOT WATER SYSTEM
}

\author{
A. Lindsay; R. Le Berre ${ }^{1}$; J.F. Doucet ${ }^{1}$; G. Kwiatkowski ${ }^{1}$; P. Dupeyrat ${ }^{1}$ \\ 1: EDF R\&D, ENERBAT, Avenue des Renardières, Ecuelles, 77250 Moret-sur-Loing, \\ FRANCE
}

\begin{abstract}
PV production and the consumptions of the building on which the PV is installed are not always in phase. In such a context, a coupling between PV production and local thermal systems can be an interesting solution to convert produced electricity into heat, thus storing it locally more easily than in electrochemical devices.
\end{abstract}

The PV Domestic Hot Water System (PV DHWS) presented here is a direct coupling (DC) between a PV installation and the heating element of an electric hot water tank. The main advantage of such a system is to provide hot water to a building from renewable resources by storing intermittent solar energy as heat.

The technical feasibility of PV DHWS is demonstrated through experimental and numerical considerations, both of these being complementary. A prototype of PV DHWS has been designed and installed in our outdoor test facilities near Paris, and a model of PV DHWS was developed under Modelica / Dymola and validated with collected experimental data.

$2.2 \mathrm{kWp}$ of PV panels (mono-Si) tilted at $30^{\circ}$ and facing south cover $70 \%$ of the hot water needs of a 4-person household over a year. 33\% of the annual PV production was lost (percentage of PV production that could be generated but is not due to the temperature of the water tank being at the upper limit), mainly due to vacations during which the hot water is not used. These promising results were achieved with an existing PV power plant. It would be possible to reduce the PV losses while maintaining a high solar fraction by down-sizing the installation.

System performances were simulated under various configurations and compared to the performances of more conventional hot water systems (solar thermal). Given the low prices of PV modules, and although thermodynamically PV DHWS makes less sense than solar thermal, an economic assessment seems to prove that this new concept could be competitive.

Keywords: Photovoltaic, Domestic Hot Water, Integration of Renewable Energy in the Built Environment, Storage

\section{INTRODUCTION}

PV modules cost around $60 \mathrm{c} €$ per Watt peak nowadays, tumbling down from above $3 € / \mathrm{Wp}$ back in 2007 and above $1 € / \mathrm{Wp}$ in 2011 [1]. Such a striking fall in prices encourages the development of residential photovoltaic systems. In the meanwhile, feed-in-tariffs for PV have decreased all over Europe and are sometimes in the same range or below the price of electricity from the grid. In this context, it will be in the interest of the owner of rooftop PV to keep for his own use as much of the generated electricity as possible rather than sell it back to the grid.

Unfortunately, PV production and the consumptions of the building on which the PV is installed are rarely in phase, especially in the residential sector. An obvious solution is to 
store the PV electricity for later use. However electro-chemical devices can be very costly and will probably not be deployed massively in the near future.

Also, whereas the energetic performance of building envelopes increases continuously with the evolution of regulations and standards, the primary energy dedicated to hot water needs remains sensibly the same for standard electric Domestic Hot Water tanks.

Storing the electricity generated by a PV array in a Domestic Hot Water tank would be a way of:

- Increasing the use of self-generated PV electricity without investing into extra equipment such as batteries

- Alleviating the primary energy needed for hot water production

The system described in this paper is a PV Domestic Hot Water System (PV DHWS) with a direct coupling (DC) between the PV installation and the heating element of an electric hot water tank, as represented on Figure 1. The main advantage of such a system is to provide hot water to a building from renewable resources by storing intermittent solar energy as heat.

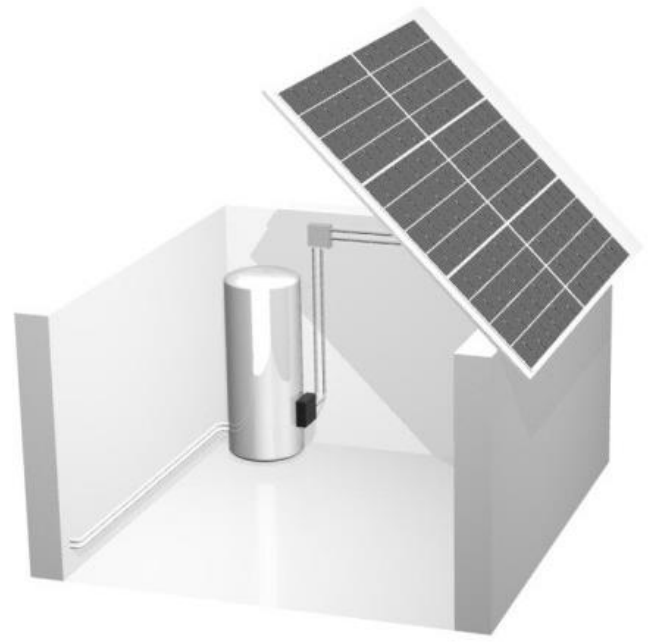

Figure 1: Concept of a PV domestic hot water system

\section{METHOD}

The technical and economic feasibility of PV DHWS were evaluated through real-life testing as well as numerical considerations.

\section{Experimentations}

An existing PV installation comprising $2.2 \mathrm{kWp}$ of PV panels (mono-Si) tilted at $30^{\circ}$ and facing south was used for the experimentations on our outdoor test platform near Paris. The power output of the array was maintained at the Maximum Power Point (MPP) by DC-DC converters and then injected into a 300L water tank with a resistive element of $3 \mathrm{~kW}$. This resistive element was powered with DC current when the solar panels produced electricity or with AC current when the PV energy was not sufficient to cover hot water needs. The control strategy was implemented on an electronic card that regulates the thermostat. Every day, the hot water consumption of a 4-person household was withdrawn from the water tank, which totals to $100 \mathrm{~L}$ of hot water at $60^{\circ} \mathrm{C}$ (M324 profile). The whole PV DHWS was instrumented and monitored. The experimental configuration is described in Figure 2. 


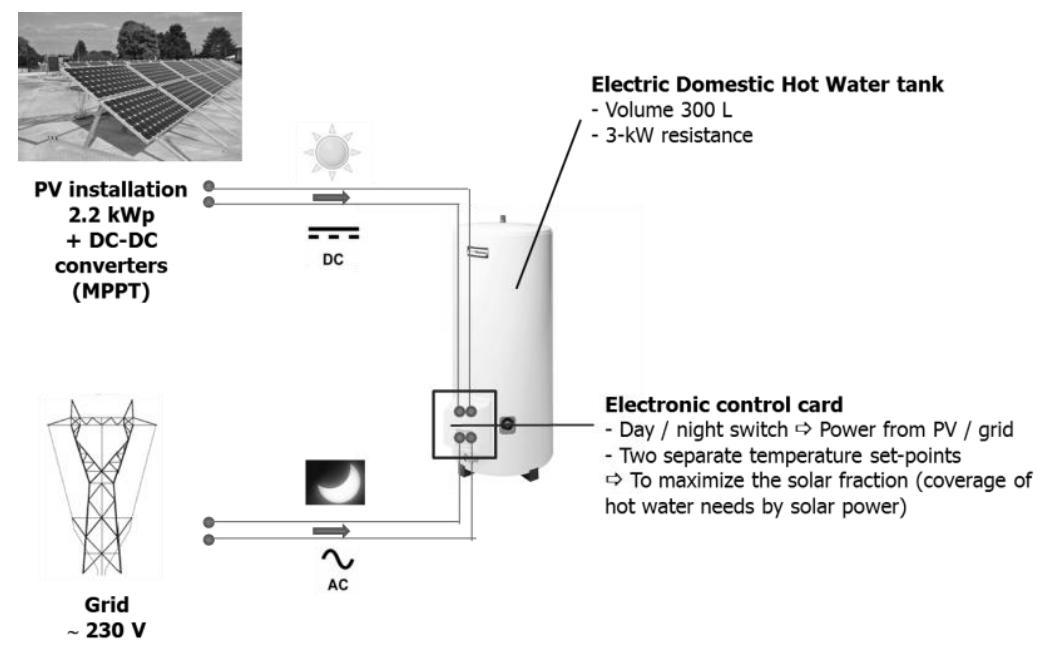

Figure 2: Experimental set-up to evaluate the concept of PV DHWS

\section{Simulations}

The prototype was modelled with Dymola, a dynamic energy simulation tool provided by Dassault Systems, using BuildSysPro [2], a Modelica library for modelling buildings and energy systems that is developed by the department of Energy in Buildings and Territories (EnerBaT) of EDF R\&D. The graphical assembly of sub-models is presented in Figure 3.

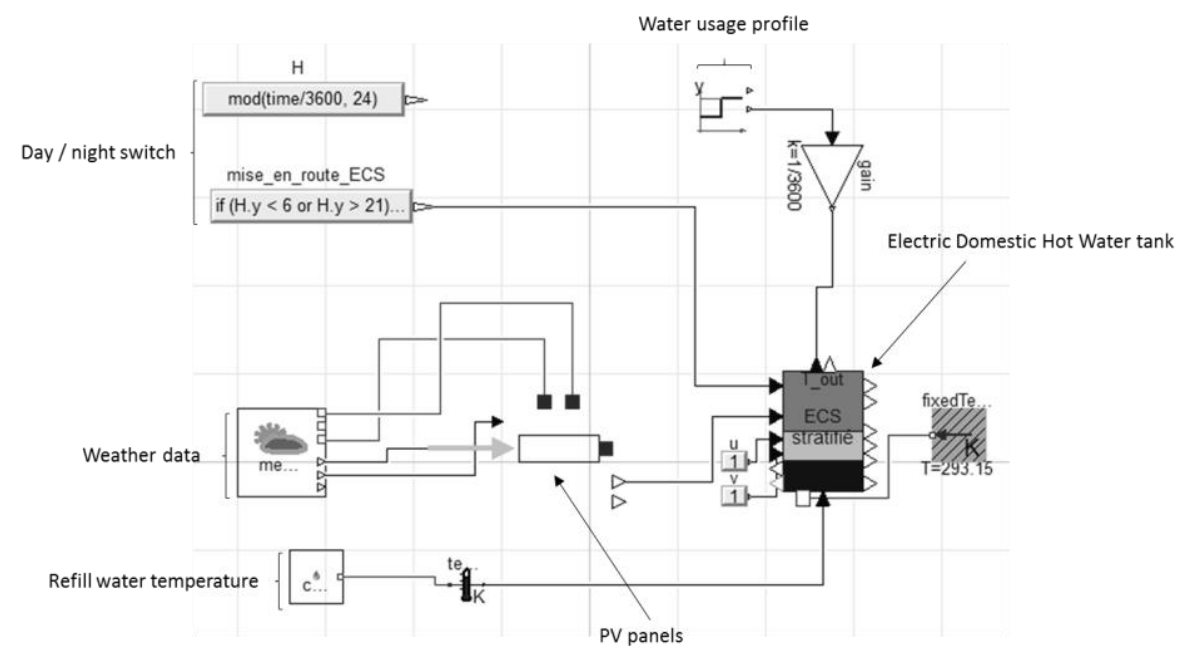

Figure 3: Numerical representation of PV DHWS under Dymola using BuildSysPro models

The model was validated and calibrated with experimental data collected from our prototype of PV DHWS. It was then used to extrapolate the behaviour of PV DHWS to different weather conditions, sizes of tanks, hot water consumption profiles, temperature set point control algorithms and sizes of PV installations.

\section{Economic assessments}

The economic evaluation of PV DHWS was done in comparison with solar thermal. In each case, the sizing of PV DHWS was adjusted in order to cover the same percentage of hot water needs as solar thermal by energy coming from the sun, should it be as heat or as electricity. 


\section{RESULTS}

Our experimental results for the PV DHWS prototype are reported in the Table 1 below in terms of solar fraction, which is the percentage of hot water needs covered by solar:

$$
\begin{aligned}
& \text { Solar fraction }(\%)=\frac{P V \text { electricity used }(k W h)}{\text { Energy used by } D H W S(k W h)}=\frac{P V \text { electricit used }(k W h)}{\text { Water heating }(k W h)+\text { Thermal losses }(k W h)} \\
& =\frac{P V \text { electricity used }(k W h)}{P V \text { electricity used }(k W h)+\text { Electricity from grid }(k W h)}
\end{aligned}
$$

\begin{tabular}{|l|c|}
\hline & Solar fraction \\
\hline Spring 2014 & $80 \%$ \\
\hline Autumn 2014 & $79 \%$ \\
\hline
\end{tabular}

Table 1: Solar fraction achieved by the prototype over two experimental periods

Over a standard sunny day (Figure 4 below), the temperature in the hot water tank increases from the night temperature set point $\left(45^{\circ} \mathrm{C}\right)$ to the day temperature set point $\left(65^{\circ} \mathrm{C}\right)$ once the sun has risen. When the day temperature set point is reached, the PV installation is disconnected, explaining the jagged aspect of the "Electric power from PV curve". Overnight, power is taken from the grid in order to maintain the temperature of the water at the night level.
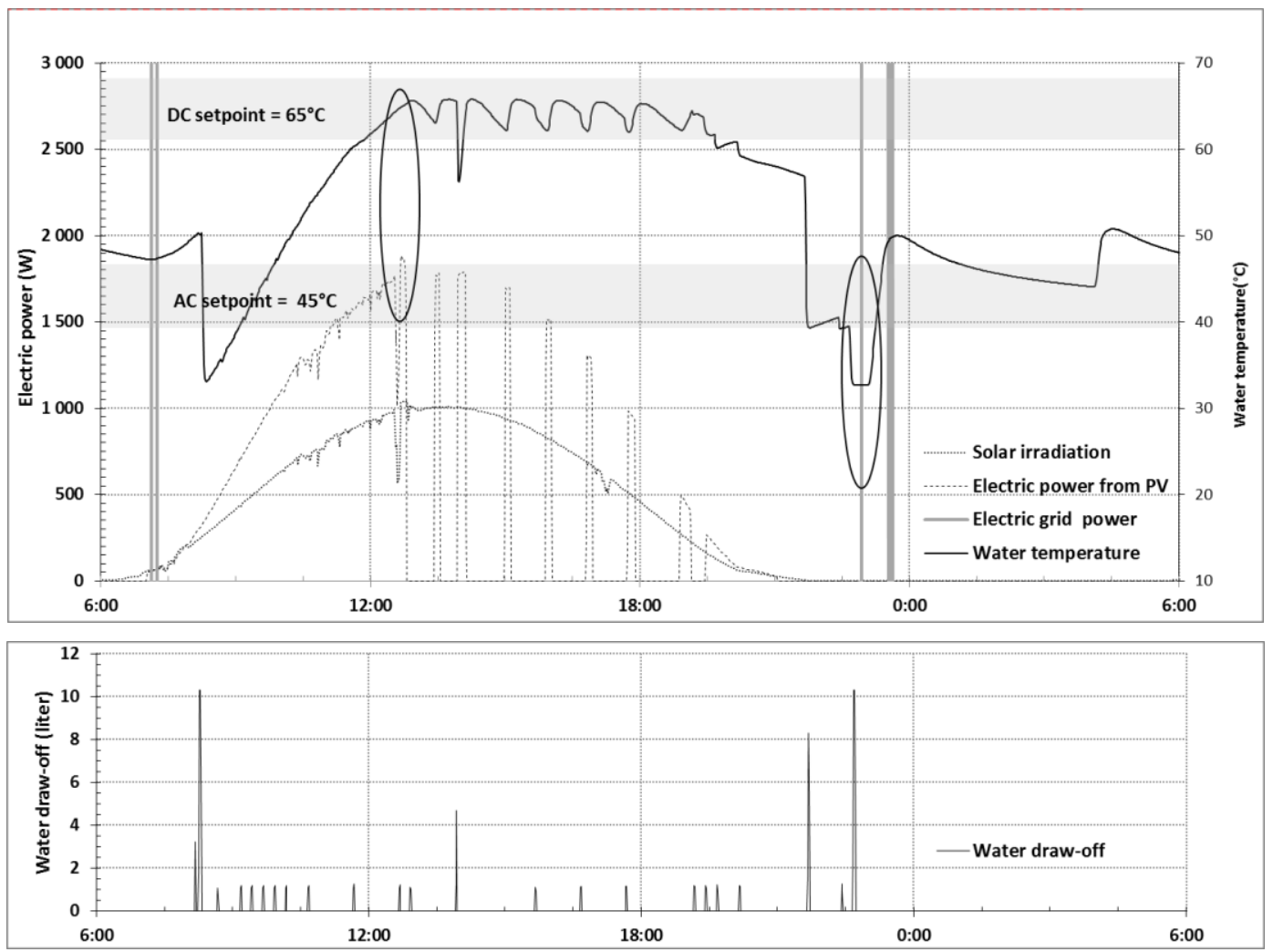

Figure 4: Experimental results of the prototype of PV DHWS for a sunny day

With the dynamic model of PV DHWS in Modelica language, calibrated with the experimental data, the solar fraction and PV losses can be estimated over a whole standard meteorological year. The PV losses correspond to the electricity that could have been generated by the solar panels but is not due to the temperature in the hot water tank being at the set point (see equation 2). Over a standard meteorological year near Paris, given the sizing 
of the PV installation and the hot water tank of the prototype and with a M324 water withdrawal profile, the solar fraction would be $70 \%$ and the PV losses would sum up to $33 \%$.

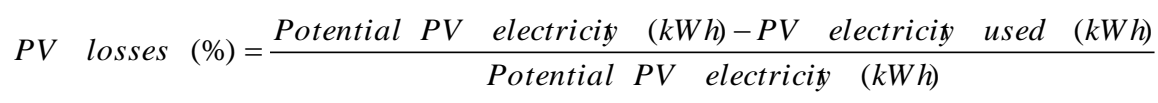

In a second part, the sizing of a PV DHWS with a 300L tank was carried out in Paris and in Nice with the goal of achieving the same solar fraction as a standard solar thermal installation.

In Paris, a conventional solar thermal system would consist in $4 \mathrm{~m}^{2}$ of absorbers for an annual solar fraction of $63 \%$. In order to cover the same percentage of hot water needs by solar, this would be equivalent to $1650 \mathrm{Wp}$ of PV for the PV DHW system, which would take up about $12 \mathrm{~m}^{2}$ of roof surface.

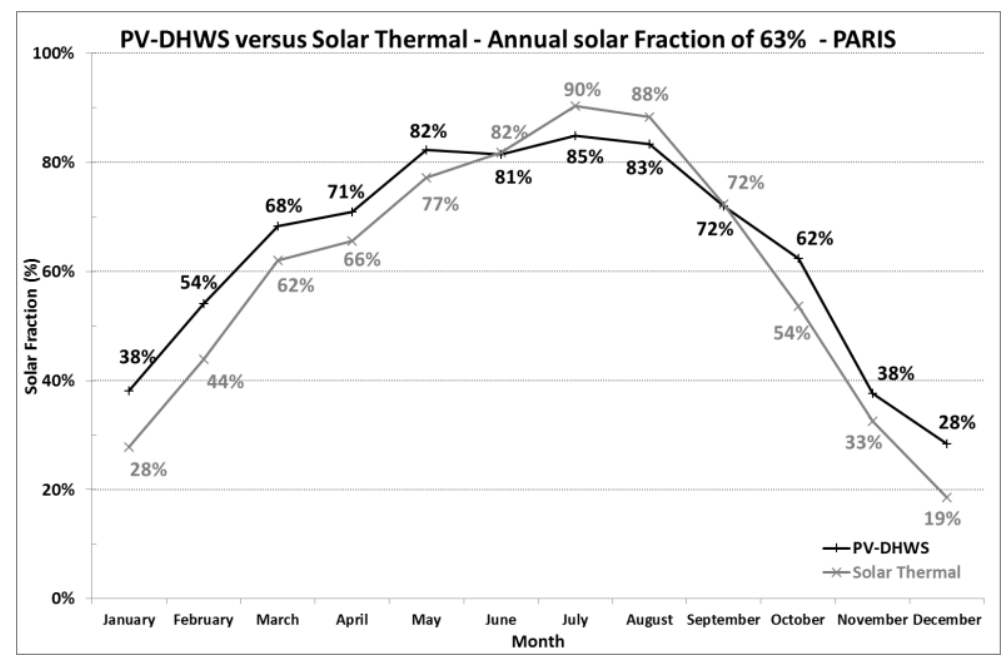

Figure 5: Solar fraction over a year for PV DHWS and solar thermal, in Paris

In Nice, a conventional solar thermal system would consist in $2 \mathrm{~m}^{2}$ of absorbers for an annual solar fraction of $55 \%$. In order to cover the same percentage of hot water needs by solar, this would be equivalent to $760 \mathrm{Wp}$ of PV for the PV DHW system, which would take up about 6 $\mathrm{m}^{2}$ of roof surface.

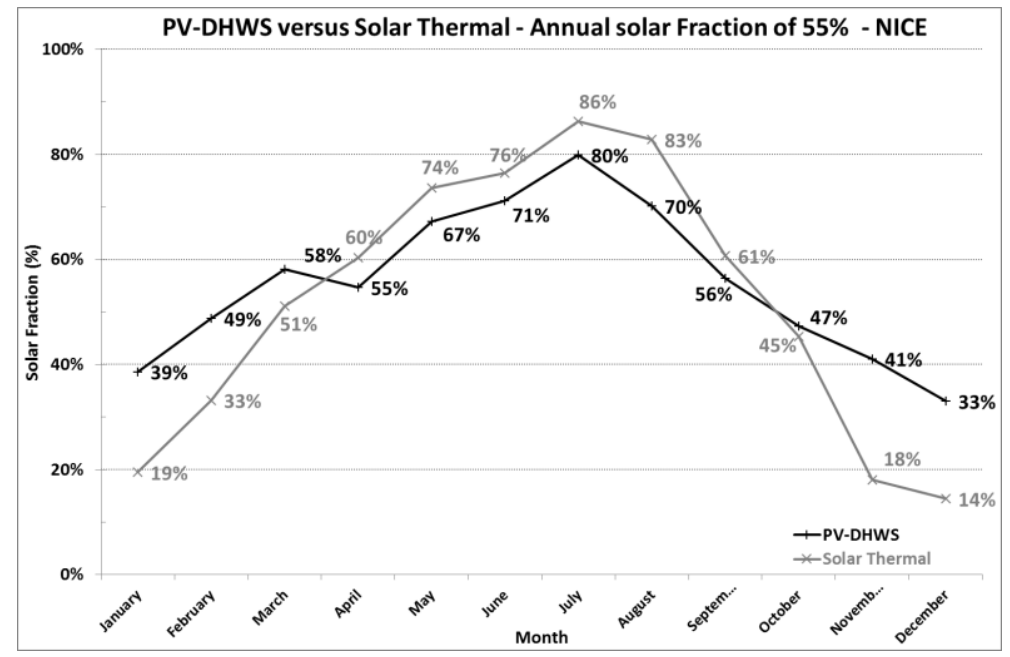

Figure 6: Solar fraction over a year for PV DHWS and solar thermal, in Nice

One can notice by looking at the previous figures that the seasonality of the solar fraction for PV DHWS is less than that of solar thermal. This is due to the fact that the electrical 
performances of solar panels increase when the temperatures are lower whereas the performances of solar thermal decrease in such cases. Furthermore, the collector surface is roughly 3 times superior for PV than for solar thermal.

For the economic assessment, the prices published by the ADEME in 2013 [3] for residential rooftop PV installations of less than $3 \mathrm{kWp}$ can be used. These were estimated in the range of 3.3 to $3.7 € / \mathrm{Wp}$, i.e. $9900 €$ to $11100 €$ for a $3 \mathrm{kWp}$ installation. $1000 €$ are necessary for the connection to the grid, which means that a non-connected residential PV installation costs on the lower side $2.97 € / \mathrm{Wp}$ and $3.37 € / \mathrm{Wp}$ on the higher side (without taking into account the further price reduction due to the absence of an inverter in the PV DHWS). The cost of a hot water tank can be conservatively judged at $1000 €$. The estimations for solar thermal are issued from a report written by the ADEME in 2013 [4].

With the same sizing of PV DHWS in Paris and in Nice presented previously, the following economic assessment can be drawn:

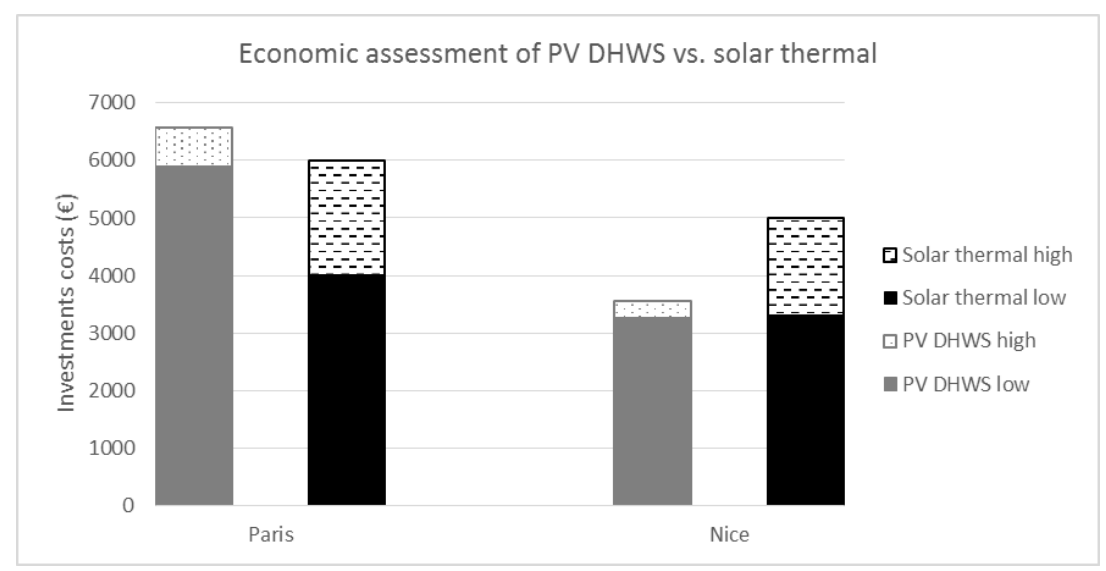

Figure 6: Investment costs of PV DHWS and solar thermal in Paris and in Nice

This figure points out the economic viability of PV DHWS with regards to solar thermal, both in the North and the South of France, on the basis of a conservative estimation of the costs.

\section{CONCLUSION}

The technical feasibility of the direct coupling of a PV installation with an electric DHW tank has been proven through the development of a prototype tested for several months on our experimental platform near Paris. With a dynamic model calibrated on experimental data, various simulations have been carried out in order to evaluate the costs of such a system. Although thermodynamically PV DHWS is less efficient than solar thermal, the economic assessments seem to show that PV DHWS is competitive all over France, with a sizing that achieves the same solar fraction as solar thermal.

\section{REFERENCES}

1. PV-magazine module price index issued from pvXchange data, website http://www.pv-magazine.com/investors/module-price-index/

2. Plessis, G., Kaemmerlen, Lindsay, A., BuildSysPro: a Modelica library for modelling buildings and energy systems. Proceedings of the International Modelica Conference 2014

3. ADEME, Le photovoltaïque en France en 2013. Version June 2014

4. ADEME, Analyse de la compétitivité et du développement de la filière solaire thermique en France. Version October 2013 